\title{
Research on the Improvement of Teachers' Artistic Accomplishment Based on the Status Quo of Contemporary Aesthetic Education
}

\author{
Weiming Liang, Yanli Yu \\ Weinan Normal University, Weinan 714099, China
}

\begin{abstract}
Contemporary aesthetic education is one of the educational methods under the contemporary cultural system, which includes contemporary educational ideas, methods, and countermeasures of art. Teachers under contemporary aesthetic education must take on the responsibility of improving their artistic qualities in this process, express differences through perceiving life, and reshape aesthetics by regulating oneself. Teachers need to be concerned about the society, and based on the present, with independent thinking, capture the essence of life and conform to the laws of art, maintain a vigilant and critical edge, advance with the times in teaching and life, as well as embody their own educational philosophies and value judgments.
\end{abstract}

Keywords: Contemporary aesthetic education; Teachers; Artistic accomplishment; Artistic quality

Publication date: December 2021; Online publication: December 23, 2021

\section{Introduction}

Artistic accomplishment refers to the quality and cultivation of people to feel, appreciate, and express a certain aesthetic ability and cognition in life and artistic works. The current situation of contemporary aesthetic education is generally well, but there are still problems, such as the old and the weak concept, the pursuit of utilitarianism, mental numbness, lagging aesthetics, as well as proliferation of images. Being a teacher under the current situation of contemporary aesthetic education, one's own artistic quality does exist, but with the passage of time and the dynamic development of aesthetic education, the issue of how to advance with the times in education and the teaching process is as a new topic that teachers of the era should pay attention to and research on. Artistic literacy is not a high-sounding term. It should be transformed into a teacher's own personal practice in the exploration of new knowledge of art through thinking and action, thus improving artistic literacy.

\section{Perceiving life and expressing differently}

Artistic literacy is a broad and grand concept. In order to improve artistic literacy, teachers have to perceive and express life in the process of teaching, dig out the essence of life, and explore the meaning of life. People only live once. How then to broaden its dimensions, increase the infinite possibilities, extend its spiritual meaning, and taste its splendor? Faced with life, it is a concrete and actual existence. Art is in life, and it is inseparable from life. Contemporary aesthetic education is carried out in concrete and daily practical teaching. Art seems superfluous in the face of reality. When people cannot guarantee the survival of life, art is almost "useless" and has no practical meaning. However, it has inspiring power and motivation for life. It must be considered a priori in order to prevent suffering and misfortune from happening. Every teacher in contemporary aesthetic education is a physical existence. The physical body is the bearing of 
perceiving the outside world and life, and it is also the channel of aesthetic education. This is the difference between them and sentient beings. In this context, teachers have dual identities of art and education; they can better feel the turmoil of the world and the reality outside the body as well as understand the pain in suffering and the excitement in joy. When shouldering the mission of aesthetic education and artistic creation, teachers would always be the presence of the soul.

It is precisely because of the empathy of teachers when facing reality and life that such concepts in aesthetic education can be taught to students and aesthetic education can be distinguished from ordinary subjects with the richest and most complex human emotions and consciousness awakening. Aesthetic education brings aesthetic feelings to students, changes their hearts, and encourages them to trace the source of life as well as the meaning of existence in a spiritual world. Under contemporary aesthetic education, teachers have to use their own super experience to foresee the future educational value and spiritual purpose, restore the value of art education with the foresight of artistic life consciousness, and provide more reasonable as well as intellectual programs for aesthetic education, thereby enhancing their own artistic quality.

\section{Regulating itself and reshaping aesthetics}

Aesthetic cognition is the result of the continuous increase of people's knowledge reserves, the continuous improvement of their understanding of life and artistic beauty, as well as the continuous review and promotion of their growth environment. The degree of aesthetic cognition varies from person to person, and the aesthetic character of teachers themselves under contemporary aesthetic education is constantly being reshaped and improved as time progresses. The process of aesthetic reshaping is a process of constantly denying the past and the result of an active search for new knowledge. The cognition in the past will be washed away with new knowledge, and the past will also be subverted on the road of art with breakthrough inspirations. "Beauty is not only an objective existence that does not depend on our will, but rather, it affects us, educates us, and enhances the realm and interest of life ${ }^{[1]}$." The aesthetics of teachers will continue to change with the development of the times. It is undergoing reshaping, thus making the road of contemporary aesthetic education more firm and powerful. In the process of reshaping their own aesthetics, they have improved their aesthetic qualities.

\section{Focusing on the society and thinking}

Upon the impact of the consumer era and post-industrial civilization, fragmented information is overwhelming, people's perception of themselves is numb and passive, individuals lack choices, and souls have nowhere to rest. Entertainment information and all kinds of leisure projects are leading the public to a vulgar and spiritual degeneration by means of inducing and pleasing; in addition, aesthetic education is facing greater challenges. Aesthetic education also needs an outlet to provide guidance for human beings with a weak sense of civilization, and it is imperative to improve artistic cultivation. Art teachers need to pay attention to the society, the changes in the people and the environment in the current society, as well as to the spiritual and cultural aspects of the society, in order to analyze various social problems and disputes from a keen perspective, think independently, call for conscience, and engage in a unique artistic way. Teaching activities guide students to improve their thinking and concepts, introduce practical problems into the classroom, allow teachers and students to analyze social problems through interactions, as well as combine excellent work cases to enlighten students in directing their attention to the society as a generation of artistic creation. Paying attention to the society itself is also paying attention to oneself. The diverse richness and problem states presented by the society often become the focus of attention among art practitioners. Thinking about social issues as well as allowing art and education to progress parallelly are 
some commitments in ensuring their works ensue warnings to the society. It is the duty of art.

However, regarding aesthetic education in the field of education, the stale dogma is like a shackle that binds the hands and feet of aesthetic education workers. The status quo of aesthetic education especially in elementary and middle schools is the most significant. Blind utilitarianism, chasing grade examinations, and entering excellent schools have destroyed the true essence of aesthetic education. Aesthetic education has fallen into the interests of the industry, incapacitating itself from escaping the antagonism, and falling in full crisis. Due to the professional characteristics, aesthetic education's attention to the social status quo would make art teaching and art creation present an ecology. Under the double torture, what a teacher conveys to students should be great, ethical, and assume the true responsibility and function of aesthetic education.

\section{Grasping the essence and conforming to the law}

The essence of aesthetic education is the aesthetic education that cultivates students' ability to feel, recognize, appreciate, and create beauty in a certain dimension. Teachers must understand this essence in aesthetic education and further identify all aspects of this essence in teaching and life, so as to improve in aesthetic ideals, aesthetic character, and artistic quality. However, this form of aesthetic education is to provide a direction goal for deeper spiritual aesthetic education, where educators need to grasp the essence and aesthetic taste of life as well as enhance the aesthetic realm of education. It also means returning to being a human being by seeing the essence from the phenomenon when facing the status quo of aesthetic education and grasping this ecological chain to explore a new realm of aesthetics.

As aesthetic education moves from a narrow sense to a broader sense, teachers' artistic qualities are constantly being optimized and improved. In the contemporary era of the substantial revolution in aesthetic education, teachers should implement this substantive content in their works based on concrete reality and reasonable combination of teaching. The frankness of aesthetic education, the yearning for the students' desire for beauty, and the improvement of their own artistic literacy should all start from the essence, in line with the purpose of cultivating qualified people and in accordance with the laws of education and teaching to carry out practical exploration. Aristotle once divided the functions of aesthetic education into three categories: education, purification, and spiritual enjoyment. Adhering to the essence of aesthetic education and carrying it out personally, grasping the essence of life, thinking deeply about the meaning of human existence, as well as educating students to understand the laws and development direction of beauty on the basis of all-round development are the emphasis. Choosing the essentials in the dynamic changes of aesthetics is in line with the development of the times and the laws of aesthetic education. It improves students' artistic quality and at the same time their own selves.

The current situation of contemporary aesthetic education still has many drawbacks while maintaining an overall good state. With the collision of the material age and spiritual civilization, culture and art have become the real demands of the people. The inheritance of a wide range of knowledge and culture as well as the cultivation of artistic literacy have become necessary skills for teachers in contemporary aesthetic education. "Whether a teacher is creative or not determines whether the teacher is a teacher or an educator

[2]." At the same time, the creativity of a new era of aesthetic education also determines the reputation of its educator. The improvement of artistic literacy is the result of the joint efforts from many aspects. It is the overall and stable development of the artistic quality, cultivation, and artistic creativity cultivated among teachers. It has a more comprehensive and higher-level cognition. It is not a dogma, nor is it subjective, but a spiritual way of being. Studying the improvement of teachers' artistic quality would help to improve the teaching level in an all-rounded way, perfect the aesthetic image, promote harmony in the society, advertise free will, and also provide a boost to the progress of civilization. 


\section{Disclosure statement}

The authors declare that there is no conflict of interest.

\section{References}

[1] Zong B, 2010, Meiyi, Peking University Press, Beijing, 12.

[2] Hu Z, Bao X, 2011, Introduction to Teachers' Artistic Quality, Peking University Press, Beijing, 23. 